\title{
Ön çapraz bağ yaralanmalarında fizik muayene, görüntüleme ve tanı
}

\author{
Physical examination, imaging and diagnosis in anterior cruciate ligament injury \\ Hasan Bombacı
}

Sağlık Bilimleri Üniversitesi, Haydarpaşa Numune Eğitim ve Araştırma Hastanesi, Ortopedi ve Travmatoloji Kliniği, İstanbul

Ön çapraz bağ (ÖÇB) yırtığı dizde sık karşılaşılan bağ lezyonlarından biridir. Daha çok cerrahi tedaviye başvurulan bu yaralanmada ideal cerrahi teknik konusunda arayış sürmektedir. Konservatif tedavi tercih edilen genç ve aktif olgularda ise instabilite ve buna bağlı olarak dizde ilave lezyonlarla sıkça karşılaşılmaktadır. Uygun tedavinin zamanında uygulanması bu açıdan önemlidir. Bir ÖÇB yırtığını ortaya koymak için yaralanmanın oluş mekanizmasının yanında, muayene bulguları, bazı özgün testler ve ayrıca manyetik rezonans (MR) gibi görüntüleme yöntemlerinden yararlanılır. Fakat hiç birisi kesin bilgi sağlamaz. Özgün testlerden Lachman testi, pivot şift testi veya son zamanlarda tarif edilen lever belirtisi testlerinden birinin pozitif olması yüksek oranda ÖÇB yırtığını düşündürür. Birden çok testin ya da bulgunun pozitif olması ise teşhis ihtimalini çok yükseltir. MR görüntüleme teşhiste altın standart olarak kabul edilmektedir. Ancak nadir olarak özellikle kısmi ÖÇB yırtıklarında son kararı vermek için artroskopik değerlendirmeye de ihtiyaç duyulabilir.

Anahtar sözcükler: ön çapraz bağ; fizik muayene; teşhis testleri; $\tan$

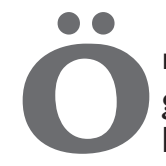

n çapraz bağ (ÖÇB) yaralanmaları dizde sık görülen bağ lezyonlarından biridir. Özellikle kadın sporcular futbol ve basketbol gibi sporlarda erkeklere kıyasla daha fazla yaralanmaya maruz kalırlar. ${ }^{[1]}$ ÖÇB'nin konservatif tedavisi dizde laksite ve instabilite ile sonuçlanabilir. Ayrıca dizde ilave yaralanmalara da zemin hazırlar. Bu yüzden özellikle genç yaşlarda çoğunlukla cerrahi tedavi tercih edilir. Değişik hasar derecelerinde meydana gelen ÖÇB yaralanmalarında doğru teşhis önemlidir. Ancak özellikle kısmi ÖÇB yaralanmalarının teşhisi zordur. Ayrıca yaralanmanın erken döneminde ve geç döneminde klinik bulgular da farklılık gösterebilir. Sözgelişi akut safhada travmaya bağlı adale spazmı

\begin{abstract}
Anterior cruciate ligament (ACL) rupture is one of the frequently encountered ligament lesions in the knee. In this injury, which is mostly treated with surgical treatment, the research for the ideal surgical technique continues. In young and active cases, in who conservative treatment is preferred, instability and related to this, additional knee lesions are frequently encountered. Timely implementation of appropriate treatment is important in this regard. To reveal an ACL rupture, beside the mechanism of injury, examination findings, some specific tests and also imaging methods such as MR are used. But none provides precise information. Being positive of one of the specific tests of the Lachman, the Pivot shift, or the recently described Lever tests, is highly suggestive of $A C L$ rupture. More than one positive findings or test increase the probability of diagnosis very much. MR imaging is considered the gold standard in diagnosis. However, rarely, arthroscopic evaluation may also be needed to make the final decision, especially in partial ACL ruptures.
\end{abstract}

Key words: anterior cruciate ligament; physical examination; diagnostic tests; diagnosis

- İletişim adresi: Prof. Dr. Hasan Bombacı, Sağlık Bilimleri Üniversitesi, Haydarpaşa Numune Eğitim ve Araştırma Hastanesi, Ortopedi ve Travmatoloji Kliniği, Tıbbiye Cad. Üsküdar, İstanbul Tel: 0216 - 4144502 / 1590 e-posta: bombacih@hotmail.com

- Geliș tarihi: 28 Mart $2020 \quad$ Kabul tarihi: 7 Nisan 2020

veya şişme nedeni ile "Lachman bulgusu" veya "pivot şift" bulgusu tespit edilemeyebilir. Bu yüzden muayenenin anestezi altında yapılması daha sağlıklıdır. Bunun dışında ÖÇB yaralanmasına diğer eklem içi ve eklem dışı yaralanmalar eşlik ettiği durumlarda da teşhis zorlukları mevcuttur. O zaman da doğru teşhise görüntüleme yöntemleri kullanılarak varılabilir. Özellikle de kısmi ÖÇB yırtıklarında doğru teşhis için, görüntüleme yöntemlerindeki hızlı gelişmelere rağmen, artroskopik muayeneye ihtiyaç duyulabilir. Bu bölümde ÖÇB yaralanması teşhisinde kullanılan fizik muayene, klinik bulgular, görüntüleme yöntemleri ve bazı özgün muayene manevralarından bahsedilecektir. 


\section{ANATOMI}

Tibia platosunun orta anterioruna yapışan ÖÇB lifleri diğer tarafta lateral femoral kondil iç yüzüne yapışır. Tibiadaki yapışma yerindeki konumuna bağı olarak önceleri anteromedial $(A M)$ ve posterolateral $(\mathrm{PL})$ demet olarak iki kısmı olduğu iddia edilse de son zamanlarda bu ayırımın daha çok işlevsel bir anlamı olduğu kabul edilmektedir. ${ }^{[2-4)}$ AM demet dizin öne translasyonunda birincil kısıtlayıcı iken, PL demetin tibial iç rotasyonu kısıtlayıcı etkisi vardır. ${ }^{[5]}$ ÖÇB'nin bu anatomik-biyomekanik özelliğinin kısmi ÖÇB yırtıklarında bağın hasar gören kısmının tespiti açısından önemi vardır.

\section{HASTANIN DEĞERLENDIRILMESI}

\section{Hikâye ve Bulgular}

ÖÇB yaralanması şüphesi olan hastada muayene, yaralanma mekanizmasının sorgulanması ile başlar. Yaralanma "kontakt" (temas ile) ya da "nonkontakt" (temas olmadan) mekanizmalar ile olabilir. ÖÇB yaralanmalarının büyük oranda nonkontakt mekanizmalara bağlı olması büyük bir kısmının önlenebilir olduğunu da gösterebilir. ${ }^{[6]}$ Nonkontakt mekanizmada ÖÇB yaralanması genellikle ayak yerde sabit, diz valgus pozisyonunda iken gövdenin ters yönde dönmesi sonucu meydana gelir (Şekil 1). Genç bayan sporcularda daha sık ortaya çıkan ÖÇB yaralanmalarının nöromusküler çalışma programları ile azaltılabileceği gösterilmiştir. ${ }^{[7]}$

Bu rotasyon mekanizmasında travma hafif ise yalnız PL demet yaralanırken daha şiddetli travmalarda AM demet ya da ÖÇB'nin tamamı yaralanır. ${ }^{[8]}$ ÖÇB'nin tam yırtıklarında hasta bir "pop" sesi duyar veya dizde bir kopma hissi algılar. Kısa süre içerisinde dizde effüzyon oluşur. Oyuna devam edemez. Yaralanmanın hemen sonrasında ya da kısa bir süre sonra dizin kontrolünde anormallik (instabilite) hisseder. Diğer taraftan kısmi ÖÇB yırtığı olan hastalarda instabilite bulgusu gelişmeyebilir. Dolayısıyla yaralanma sonrası oyuna dönmek mümkündür. Ancak hasta hasar gören dokunun büyüklüğüne bağlı olarak zaman zaman effüzyon ve diz ağrısından şikâyet edebilir. Özellikle hızla gelişen effüzyon ÖÇB yaralanmasını destekleyen önemli bir bulgudur. Wagemakers ve ark., yaptıkları çalışmada effüzyon, travma esnasında duyulan "pop" sesi, dizde kayma hissi ve öne çekmece belirtisinin manyetik rezonans (MR) kesitte gösterilen ÖÇB yaralanması ile anlamlı derecede ilişkili olduğunu tespit etmişlerdir. ${ }^{[9]}$

ÖÇB yaralanması, kısmi ÖÇB hasarı olan hastanın yeni bir travma ile tam yırtığa dönüşmesi şeklinde meydana gelebileceğinden; hastaya son yaralanma öncesi dizinin travmaya maruz kalıp kalmadığı, travma oldu

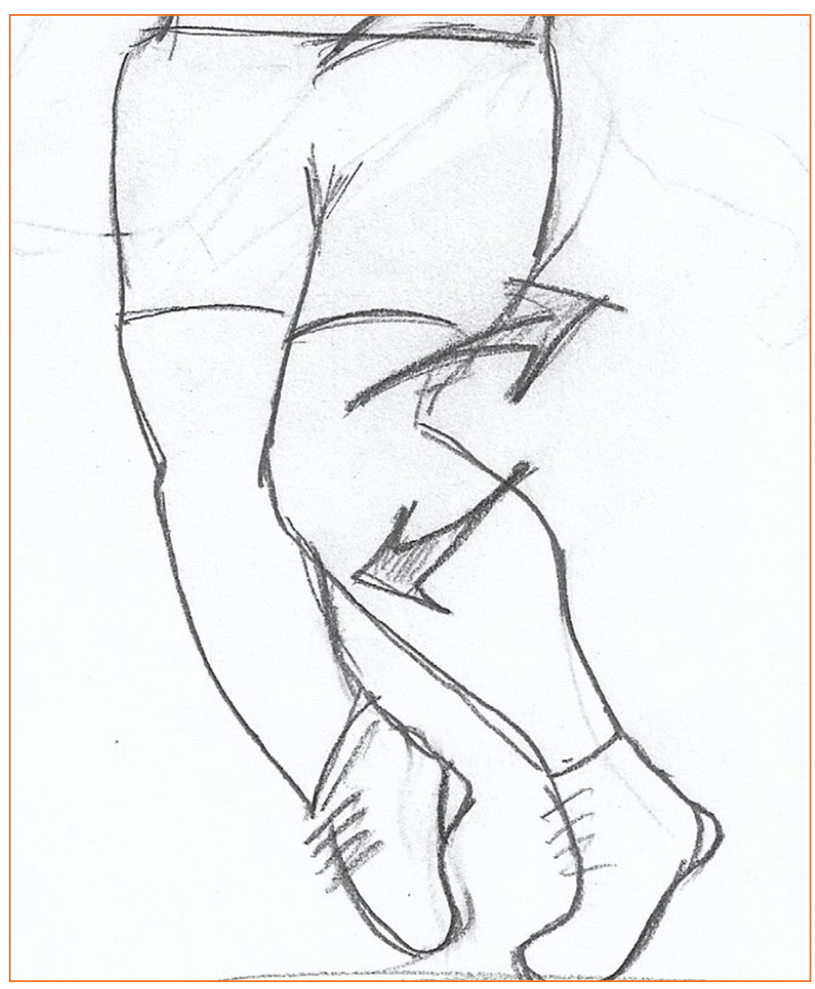

Şekil 1. ÖÇB yaralanma mekanizması. Ayak yerle temas halinde iken femur diz ekleminin üstünden iç rotasyona, diz valgusa zorlanır.

ise ilk defa ne zaman olduğu, dizinde kayma veya boşa gelme hissinin olup olmadığı sorulmalıdır. Fayard ve ark., yaptıkları çalışmada kısmi ÖÇB yaralanması olan hastaların \%39'unun tam yırtığa döndüğünü ve hastaların yarısında eşlik eden bir menisküs lezyonu geliştiğini tespit etmişlerdir. ${ }^{[10]}$

ÖÇB yaralanmalarında akılda tutulması gereken bir diğer konu eşlik eden kırıklar ve diğer eklem içi veya dışı yaralanmalardır. En sık eklem içi yaralanma menisküslerde olur. Menisküs yaralanması olan hastalarda takılma ve kilitlenme bulguları sıklıkla eşlik eder. Kıkırdak lezyonlarında da takılma ve sürtünme bulgusu olabilir. ÖÇB yaralanmasına eşlik eden diğer bağ yaralanmalarını ortaya çıkarmak için özgün muayene manevraları; arka çapraz bağ için "posterior çekmece testi”, posterolateral köşe için "eksternal rotasyon rekürvasyon testi", dış yan bağ için "varus stres testi" vs. tanıyı koymaya yardımcı olabilir (Şekil 2).

ÖÇB yaralanmaları ile birlikte son zamanlarda gündemde olan bir diğer yaralanma anterolateral bağ$\operatorname{dır}(A L L){ }^{[11]}$ ÖÇB yırtık hastalarda \%10,8 ile \%62,5 oranında ALL bağ yaralanmasının eşlik ettiği bildirilmiştir. ${ }^{[12]}$ Özellikle dış yan bağ, popliteus tendonu, 


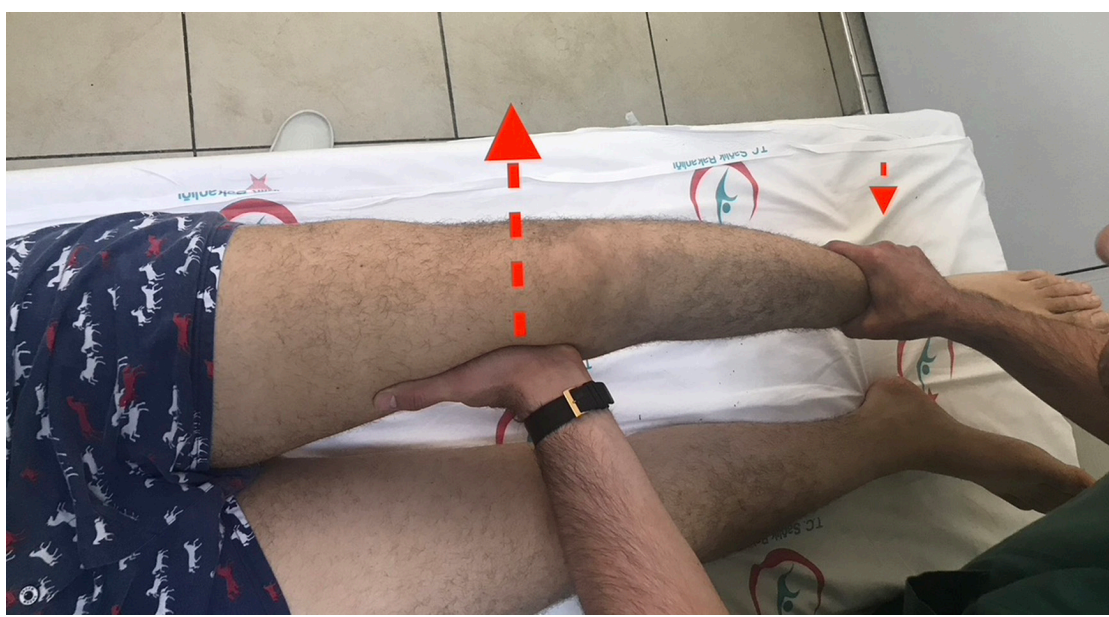

Şekil 2. Varus stres testi. Ayak bileğinden yakalanan bacak diz tam ekstansiyonda ve yaklaşık $30^{\circ}$ fleksiyonda iken dizin iç tarafına konan diğer elin yardımı ile varusa zorlanır. Dizin, karşı dize göre anlamlı derecede varusa gelmesi dış yan bağ yanında ÖÇB'nin de koptuğunu düşündürür.

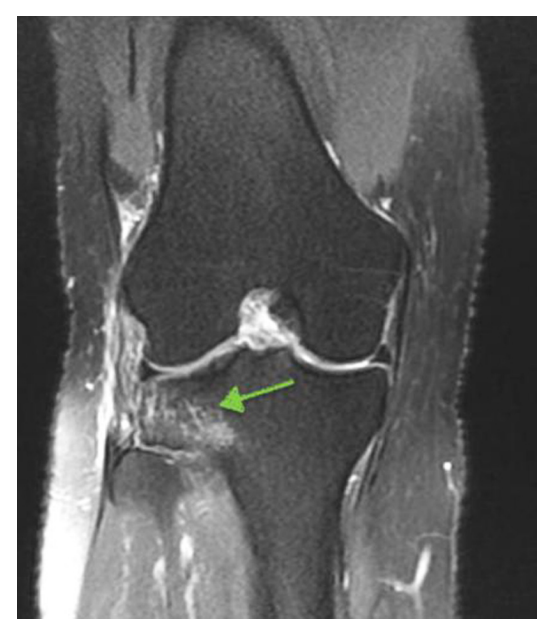

Şekil 3. Dizin posterolateral bölgesinden geçen koronal planda MR kesiti. T2 ağırlıklı görüntüde kemik iliği ödemi (yeşil ok) görülmekte. iliotibial bant (ITB) ve lateral tibia ve femurda kemik iliği ödemi olan hastalarda ALL lezyonları daha sık görülmektedir (Şekil 3). ${ }^{[12]}$ Bu hastalarda ayrıca pivot şift testi yüksek derecede pozitiftir. ${ }^{[11]}$ ALL yaralanmalarının bir belirtisi olan "Segond kırı̆̆”" uygun pozisyonda çekilmiş direkt diz grafisinde görülürken, MR ve ultrason ile yalnız ALL'yi ilgilendiren hasarlar yüksek oranda ortaya konabilir. Gerek daha geniş kemik iliği ödemi gerekse beraberindeki Segond kırığı, ALL yırtığının ÖÇB'ye eşlik eden travmaların daha yüksek enerjili olduğunu düşündürmektedir.

\section{Fizik Muayene}

\section{Varus/valgus stres testi}

$\mathrm{Bu}$ test yapilırken hasta muayene masasında sırtüstü yatar. Bacak muayene masasından yan tarafa alınarak ayak bileğinden varus ya da valgusa zorlanırken diğer el dizin iç ya da dış yanından varus/valgus stresine karşı koyacak şekilde destek olur. Özellikle ekstansiyonda ileri derecede varus/valgus açılması iç ya da dış yan bağ yanında çapraz bağın da koptuğuna delalet eder (Şekil 2).

\section{Lachman testi}

Lachman testi esas itibariyle dizin öne translasyonunu göstermek için kullanılır. Rotasyonel instabiliteyi göstermez. Lachman muayenesi mutlaka diğer diz ile karşılaştııılarak yapılmalıdır. Kısmi yırtıklarda hasarın lokalizasyonuna bağlı olarak ÖÇB yaralanması olan dizde diğer dize göre bir miktar esneme olabilir. Ancak son nokta (end point) yine de serttir. Dolayısıyla farkı

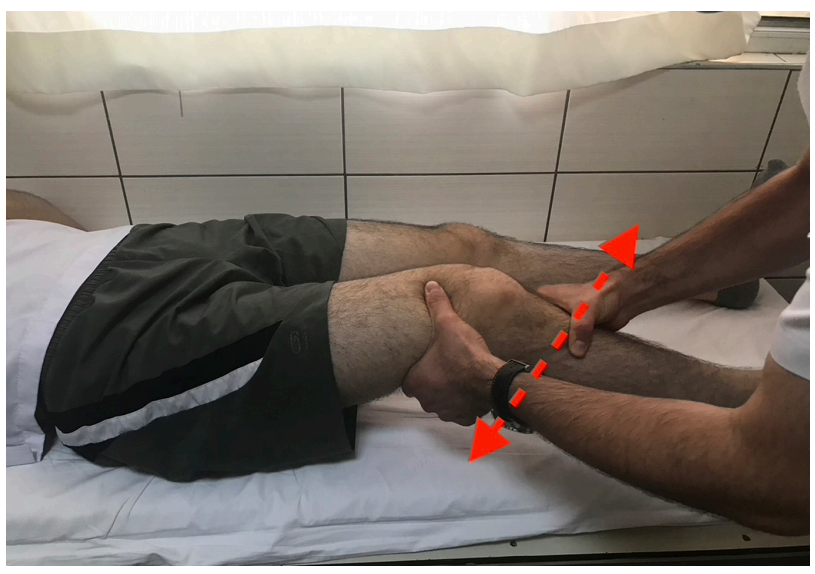

Şekil 4. Lachman testi. Diz yaklaşık $15^{\circ}$ fleksiyonda iken femur alt ucu bir elle sabit tutulur. Tibia üst ucu kavrayan el ile tibia öne doğru hareket ettirilir.

anlamak her zaman kolay olmayabilir. Hole ve ark., yaptıkları çalışmada ÖÇB'nin 3/4'ü kesilene kadar aradaki farkın anlaşılamayacağı belirtilmiştir. ${ }^{[13]}$

Lachman testi yapılırken hasta sırt üstü yatar. Diz yaklaşık $15^{\circ}$ fleksiyonda iken muayene eden kişi bir eliyle femur alt ucunu tutarken diğer eliyle dört parmak tibia üst uç posteriorunda başparmak tibia üst uç anteromedialinde olacak şekilde tibia üst ucunu öne doğru çeker. Bu esnada tibia femura göre öne doğru hareket ederse test pozitiftir (Şekil 4).

\section{Öne çekmece testi}

ÖÇB yaralanmalarında bir diğer önemli test "öne çekmece testi”dir. Ancak bu testi yaparken dizi stabil eden diğer yapılar ÖÇB yırtığından kaynaklanan 


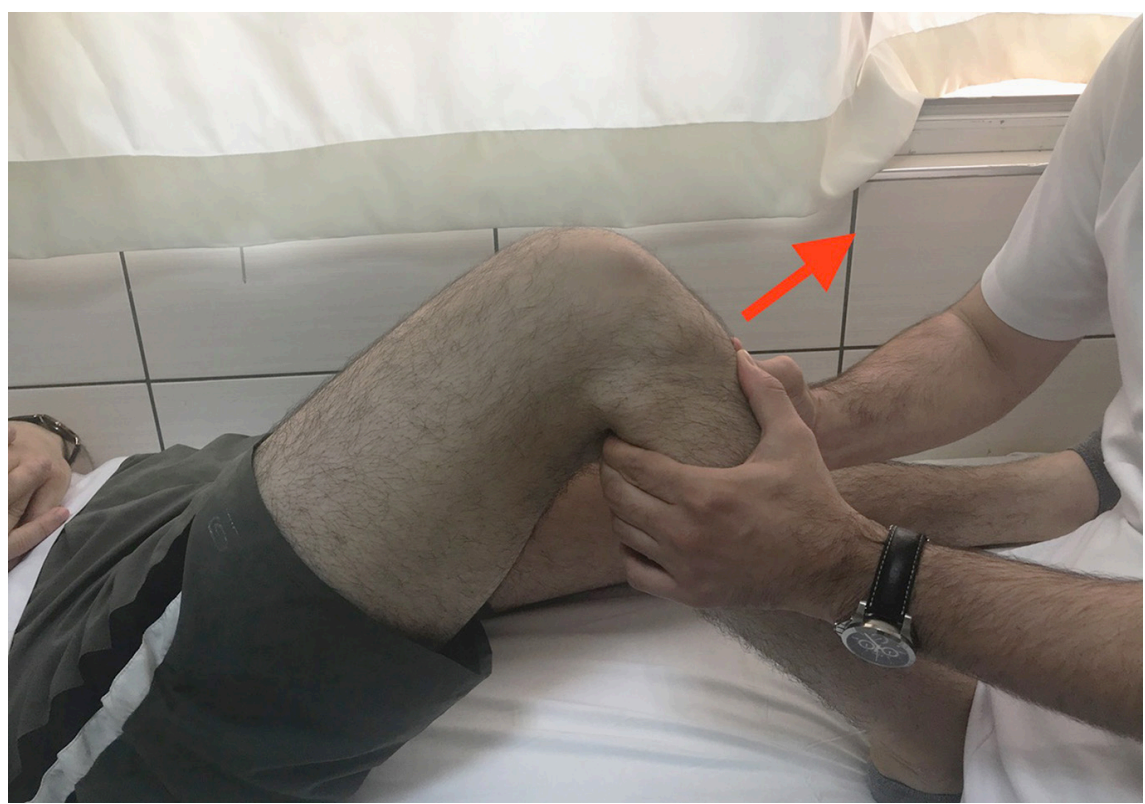

Şekil 5. Öne çekmece testi. Hasta sırt üstü yatar vaziyette, kalça $45^{\circ}$ ve diz $90^{\circ}$ fleksiyonda iken muayene eden kişi ayağı sabitlemek için hafifçe ayağın üzerine oturur. İki eli ile tibianın üst ucunu tutarak ileri geri hareket ettirir.

instabilitenin ortaya konmasını önleyebilir. Kısmi ÖÇB hasarlarından ise AM demet yırtık olgularda bu testin pozitif olma ihtimali yüksektir. Bunun dışında ÖÇB kalıntılarının çevredeki yapılarda nonanatomik bölgelere yapışma ihtimali mevcuttur. Bu durumlarda da instabilitenin zaman içerisinde bir miktar azaldığı görülür.

Bu test yapılırken hasta muayene masasında sırt üstü yatar vaziyette, kalça $45^{\circ}$ ve diz $90^{\circ}$ fleksiyonda iken muayene eden kişi ayağı sabitlemek için hafifçe ayağın üzerine oturur. İki eli ile tibianın üst ucunu tutarak ileri geri oynatır (Şekil 5). Bu manevralar tibia $15^{\circ}$ iç ve $30^{\circ}$ dış rotasyonda iken de tekrarlanır (Slocum anterior rotasyonel çekmece testi). Normal dizle karşılaştırılır. Sağlam dize göre 6-8 mm'den fazla hareket pozitif olarak kabul edilir. Bu testi yapmadan önce arka çapraz bağın sağlam olduğundan emin olmak gerekir. Aksi takdirde testin başında arkaya sarkan diz yanlış olarak pozitif olarak değerlendirilebilir.

\section{Pivot şift testi}

Dizin rotasyonel instabilitesini göstermek için kullanilır. Dizin horizontal ve sagittal stabilitesini ortaya koyan bu test özellikle anestezi altında yapıldığında daha doğru sonuç verir. ${ }^{[14]}$

Pivot şift muayenesinde hasta sırt üstü yatar vaziyette iken internal rotasyondaki proksimal tibiaya valgus stresi uygulanır. Ekstansiyondan fleksiyona getirilen diz ekleminde $20^{\circ}-30^{\circ}$ fleksiyonda (iTB'nin diz rotasyon

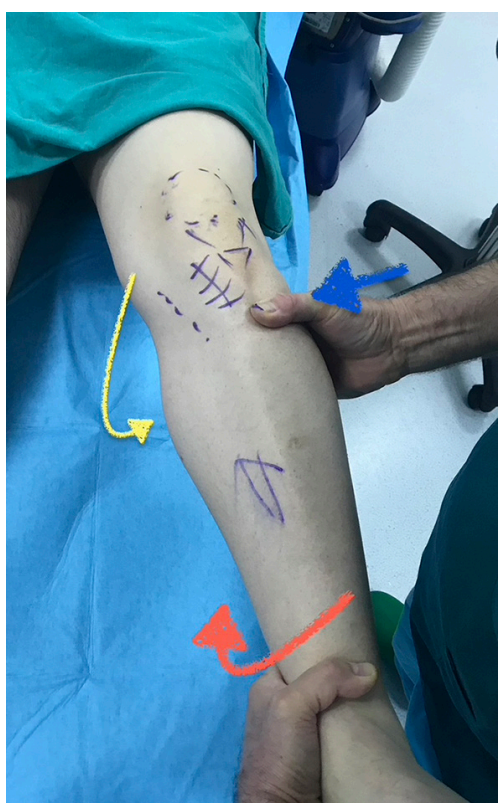

Şekil 6. Pivot şift testi. Hasta sırt üstü yatar vaziyette iken internal rotasyondaki proksimal tibiaya valgus stresi uygulanır. Ekstansiyondan fleksiyona getirilen diz ekleminde $20^{\circ}-30^{\circ}$ fleksiyonda ortaya çıkan ani subluksasyon hareketi testin pozitif olduğunu gösterir.

merkezinin posterioruna yer değiştirmesi ile) ortaya çıkan ani subluksasyon hareketi testin pozitif olduğunu gösterir (Şekil 6). Bu testin dizi fleksiyondan ekstansiyona getirerek (jerk testi), yer çekimini kullanılarak, cihaz ya da ipad için hazırlanmış uygulamalar kullanılarak yapılan varyasyonları da vardır. ${ }^{[14]}$ Derecelendirme de çok kesin sınırlar tespit edilememiştir. Bunların içerisinde en sık kullanılan "IKDC (The International Knee Documentation Committe) sınıflaması"nda instabilite "Grade 0" (normal), "Grade 1" (glide/kayma), "Grade 2" (clunk/atlama), "Grade 3" (locked subluxation/kilitli subluksasyon) olarak dörde ayrılmıştır. Dizin bağ durumunu dinamik olarak ortaya koymak için iyi bir testtir.

Pivot şift testinin tam ÖÇB yırtıklarında daha bariz olmak üzere, kısmi ÖÇB yırtıklarında PL demet hasar görmüş ise pozitif olma ihtimali vardır. Nishida ve ark., yaptıkları çalışmada ÖÇB yırtığının kronikliği arttıkça rotasyonel laksitenin de arttığını tespit etmişlerdir. ${ }^{[15]}$ Aynı çalışmada özellikle lateral menisküs olmak üzere menisküs lezyonlarının da rotasyonel laksitenin artmasına neden olduğu belirtilmiştir. Ayrıca yaralanmadan 1 yıl sonra menisküs yaralanmasından bağımsız olarak pivot şift bulgusunun daha belirgin olduğunu da tespit etmişlerdir. ${ }^{[15]}$ 
Bunun yanında dizdeki instabiliteye birincil etkili yapılar arasında tartışmalar devam etmektedir. Kittl ve ark., yaptıkları kadavra çalışmasında dizdeki öne kaymada birincil kısıtlayıcının ÖÇB olduğunu, ÖçB kesilmiş dizlerde $30^{\circ}$ fleksiyonda iTB'ın öne çekme gücünün \%31'ini karşıladığını, ALL ve anterolateral kapsülün etkisinin \%4 olduğunu bulmuşlardır. ${ }^{[16]}$ Gerek ÖÇB sağlam gerekse ÖÇB kesilmiş olgularda, yüksek fleksiyon açılarında iTB'ın yüzeysel liflerinin iç rotasyon gücünün \%56'sını karşıladığını tespit etmişlerdir. ITB'ın derin lifleri ise $30^{\circ}$ fleksiyonda ÖÇB sağlam dizlerde iç rotasyon kuvvetinin \%26, ÖÇB kesik dizlerde ise \%33'ünü karşılamaktadır. Pivot şift testi uygulanırken ÖÇB kesik dizlerde direncin \%72'si ITB tarafından karşılandığını bildirmişlerdir. ${ }^{[16]}$ Ancak Noyes ve ark.'nın yaptığı kadavra çalışmasında ÖÇB yırtığı sonucunda ortaya çıkan pivot şift subluksasyonunu ALL'ın önlemeye yeterli olmadığı tespit edilmiştir. Bu çalışmada ALL ve iTB'nin pivot-şift subluksasyonu için birincil kısıtlayıcılardan olmadığı vurgulanmıştır.[17] ALL ve iTB'nin Kittl ve ark. bulguları ile paralel olarak yüksek fleksiyon derecelerinde diz iç rotasyonunda primer kısıtlayıcı rolü oynadığı belirtilmiştir.[16] ÖÇB, iTB ve ALL'nin beraberce kesildiği olgularda "Grade 3" pivot şift bulgusunun ortaya çıktığı gösterilmiştir. ${ }^{[17]}$ Song ve ark. pivot mekanizması gerektiren spor yaralanmalarında, lateral tibial eğimi anormal olan, anterolateral kapsüler yapıların hasarlandığı ve lateral menisküs yaralanması olan hastalarda "Grade 3" pivot şift görülme ihtimalinin yüksek olduğunu tespit etmişlerdir. ${ }^{[18]}$

\section{Hughston'un jerk testi}

Bu test hasta sırt üstü yatarken yapılır. Diz $90^{\circ}$ fleksiyonda, valgus stresi altında tibia iç rotasyonda iken diz yavaş yavaş ekstansiyona getirilir. Yaklaşık $30^{\circ}$ fleksiyonda tibia öne doğru atlama şeklinde sublukse olur. Bu durumda test pozitiftir.

Lelli ve ark. tarif ettikleri "Lever belirtisi testi" ile kronik ve tam ÖÇB yırtıklarında \%100'e yakın doğrulukta testin pozitif olduğunu bildirmişlerdir (Şekil 7). ${ }^{[19]}$ Kısmi ve akut yırtıklarda "Lever belirtisi testi" ile öne çekmece, Lachman ve pivot şift testini karşılaştırdıklarında da diğer testlere göre hassasiyetinin yüksek olduğunu bulmuşlardır.

Bu testte hasta sırt üstü pozisyonda muayene masasında yatarken muayene eden hekim yumruğunu hastanın baldırının altına koyar, sonra dizin üstünden uyluğu masaya doğru bastırır. Eğer ÖÇB sağlam ise topuk masadan yukarıya doğru yükselirken, ÖÇB yırtık hastalarda topuğun masa ile teması devam eder (Lever belirtisi testi, pozitif) (Şekil 7). ${ }^{[19]}$

ÖÇB yaralanması olan hastalarda instabiliteyi sayısal olarak ölçen cihazlar da mevcuttur. Sözgelişi

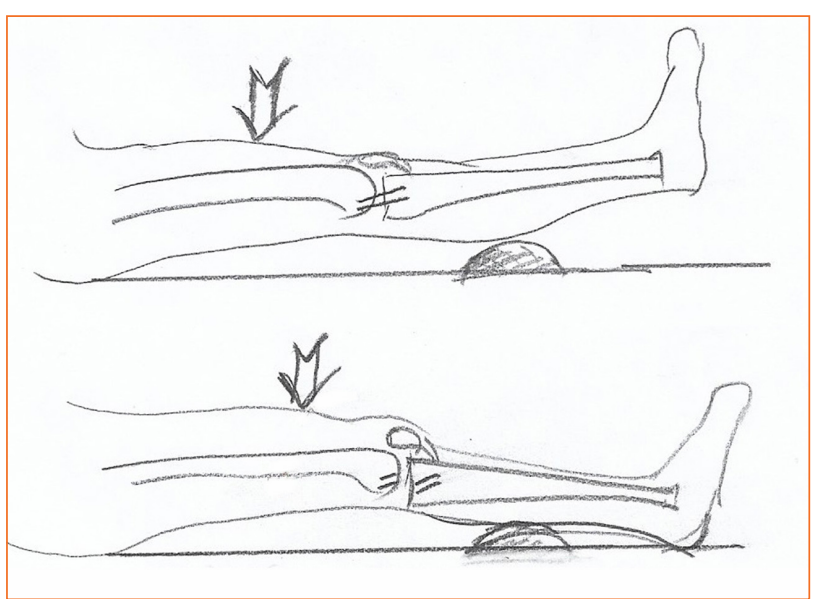

Şekil 7. Lever belirtisi testi. Krurisin posterioruna bir destek konduktan sonra femur alt ucuna zemine doğru basınç (ok) uygulanır. Bu basınçla beraber ayak zeminden yükselirse (üstteki çizim) test negatiftir, eğer zeminle teması sürdürürse (alttaki çizim) test pozitiftir.

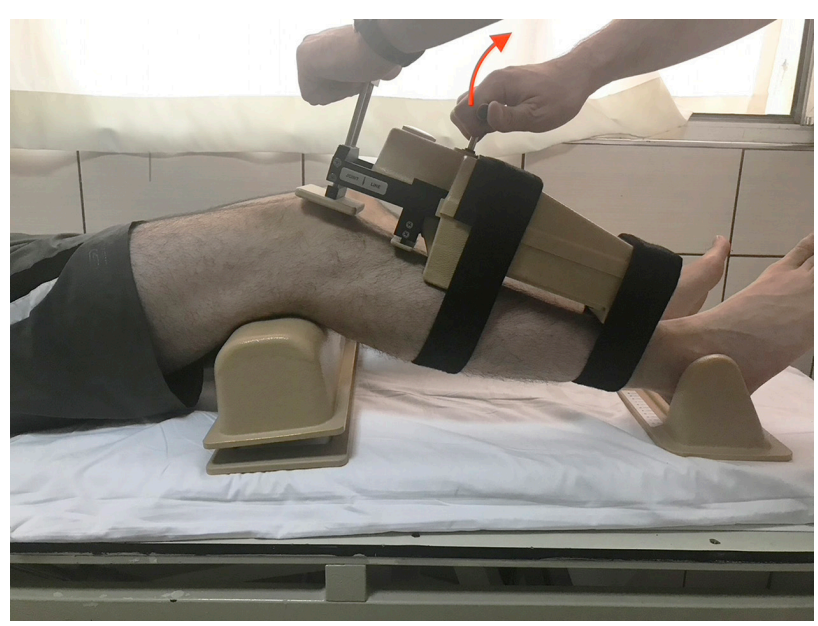

Şekil 8. KT 2000 cihazı ile ölçüm. Sağlam bacağa göre 3 mm'nin üzerindeki fark ÖÇB hasarı yönünde değerlendirilir.

KT-2000 (MEDmetric, San Dỉego, CA) cihazı ile ölçüldüğünde karşı diz ile arasında $3 \mathrm{~mm}$ ve daha az fark olan olgularda genellikle kısmi ÖÇB yaralanması tespit edilmiştir (Şekil 8). ${ }^{[20]}$ Bir diğer cihaz olan Telos cihazı ile önden stres uygulanan dizlerde deplasman miktarı radyolojik olarak ölçülerek de ÖÇB yırtıklarının boyutları hakkında fikir sağlanabilir. Ryu ve ark. ÖÇB kopuk hastalarda GNRB artrometresi (Genourob, Laval, Fransa), Lachman testi ve Telos cihazını ( $\mathrm{GmbH}$, Hungen, Almanya) karşılaştırmışlardır. ${ }^{[21]}$ GNRB artrometresinin ÖÇB'nin kopmasından sonraki ilk 10 gün içerisinde Lachman testi ve Telos cihazına göre daha doğru sonuç verdiğini tespit etmişlerdir. [21] 


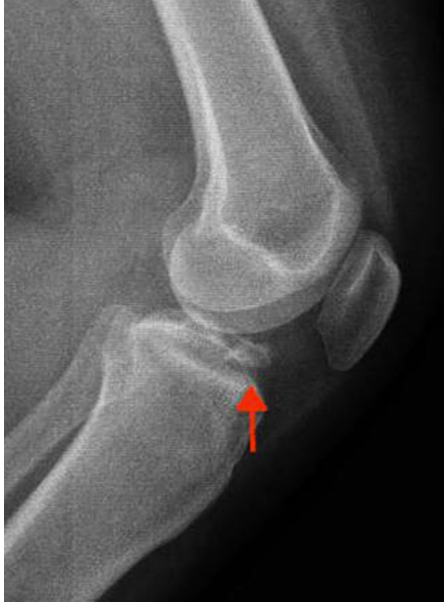

Şekil 9. Diz lateral grafisinde eminentia kırı̆̆ı (kırmızı ok).
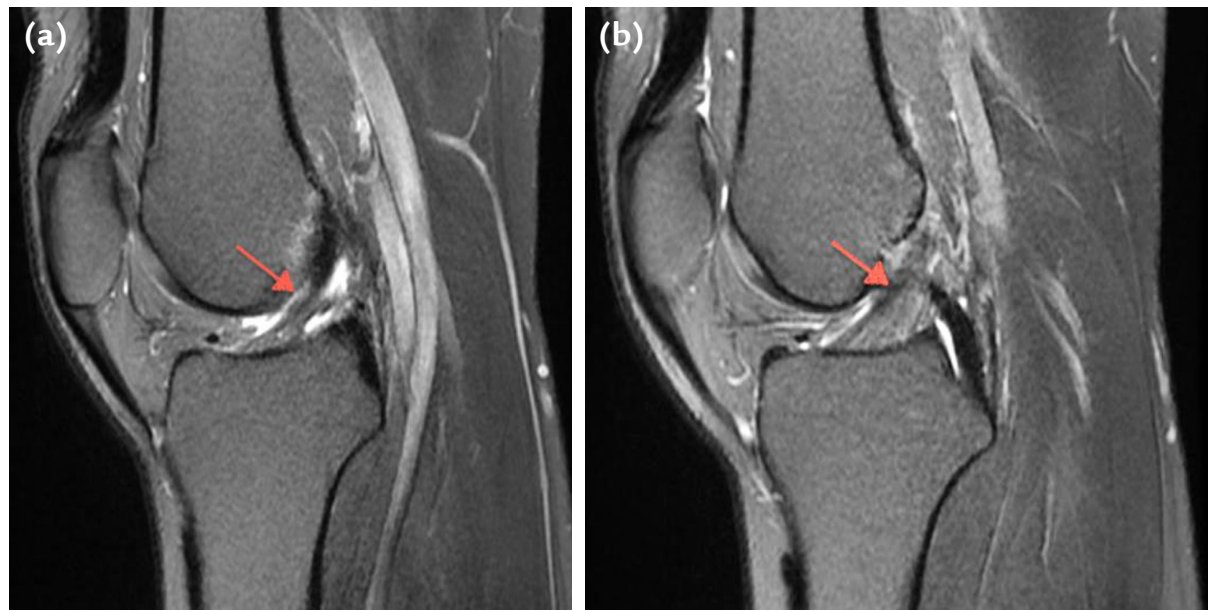

Şekil 10. a, b. T2 ağırlıklı sagittal planda normal diz MR görüntüsü. Eklem içindeki oblik yerleşimi sebebi ile ÖÇB'nin tamamı genellikle tek bir kesitte görülemez. Ancak ardışık iki kesitte (a ve b), ÖÇB'nin devamlılığı takip edilebilir.
Diğer taraftan ÖÇB yırtıklarına eşlik eden yaralanmalar yukarıda tarif edilen testlerin yapılmasını ya da doğru sonuç vermesini etkileyebilir. Sözgelişi AÇB kopuk hastalarda öne çekmece belirtisi yanlış pozitif olarak bulunabilir. Kova sapı menisküs yırtığı tibianın öne gelmesini etkileyeceği için öne çekmece testini yanlış negatif olmasına neden olabilir. Aşırı valgus instabilitesi olan hastalarda medial destek ortadan kalkacağı için ÖÇB yırtık hastalarda pivot şift bulgusunu elde etmek mümkün olmayabilir. Bu gibi durumlarda teşhiste görüntüleme yöntemlerinden yararlanılır.

\section{Görüntüleme}

\section{Direkt grafi}

ÖÇB yaralanması şüphesi olan hastalarda kırıkların ortaya konmasında yararlıdır. Özellikle genç hastalarda eminentia kırıkları ÖçB yırtığı bulgusu verir (Şekil 9). Bunun dışında ÖÇB yaralanmalarında grafide "Segond kırı̆ı̆" görülebilir. Son zamanlarda "Segond kırığı" ile anterolateral ligament (ALL) arasında bağ kuran çalışmalar mevcuttur. Ayrıca çoklu bağ yaralanmalarında dış yan bağ kopuğu olabileceği gibi fibula proksimalinde de kırıklar meydana gelebilir. Bunun gibi tibia üst uç kırıkları direkt grafide görülebilecek ek yaralanmalardır. Kronik ÖÇB yaralanması olan hastalarda yük altında çekilen direkt grafiler ile eklem aralığındaki daralma da ortaya konabilir. Buna göre ÖÇB yırtığı rekonstrüksiyonu planlanan hastalarda ÖÇB rekonstrüksiyonu yanında yüksek tibial osteotominin (YTO) gerekip gerekmediği, ya da ÖÇB ile beraber aynı seansta YTO planlanıyorsa -tibial eğimin durumuna göreosteotominin "açık kama osteotomisi" tekniği ile mi yoksa, "kapalı kama osteotomisi" ile mi yapılacağı konusunda değerlendirme yapılabilir.

\section{$M R$ görüntüleme}

ÖÇB yaralanmalarında "altın standart" MR görüntülemedir. MR ile aynı zamanda hem eklem içi ve hem de eklem dışı diğer patolojileri tespit etmek mümkündür. Kısmi ÖÇB yırtığı olan hastalarda ise ÖÇB'nin hasarlı kısmın yerini tespit etmekte kısmen yararlı olabilir. ÖÇB yaralanmalarında teşhis için genellikle T1 ve T2 ağırıklı standart kesitler yeterli olurken, kısmi ÖÇB yaralanmalarında "koronal oblik" ve "sagittal oblik" pozisyondaki değerlendirmelere ihtiyaç vardır (Şekil 10. a, b). ${ }^{[20,22]}$ ÖÇB yırtıklarında başlıca MR bulgularI; sagittal kesitlerde ÖÇB'nin ön kenarında dalgalanma, T2 ağırıklı görüntülerde yüksek sinyal görülmesi ve ÖÇB'nin devamlılığında bozulma olarak sayılabilir (Şekil 11). [23]

Bunun dışında ÖÇB yırtıklarının MR ile incelenmesinde yeni ve eski yırtıklar da farklı görüntü verir. Özellikle kronik ÖÇB yırtıklarının MR ile teşhisinde zorluklar mevcuttur. Vahey ve ark., yaptıkları çalışmada, yeni ÖÇB yırtıklarında ÖÇB dokusu MR'de ödemli görülürken eski yırtıklarda, kısmen sağlam kalmış ÖÇB liflerinin ÖÇB yırtıklarının tespitinde yanıltıcı olabileceğini bildirmişlerdir. ${ }^{[24]} \mathrm{Bu}$ hastalarda ÖÇB dokusunda ince bir devamlılık ya da bağın bir kısmında açılanmanın gözlenmesi ÖÇB yırtığı konusunda uyarıcı bulgular olarak tanımlanmıştır. ${ }^{[24]}$ Lee ve ark., MR bulgularını klinik testler ve artroskopi ile karşılaştırdıkları çalışmada, MR bulgularının hassasiyetinin \%94, öne çekmece testinin \%78, Lachman testinin ise \%89 olduğunu tespit etmişlerdir. ${ }^{[23]}$ Son zamanlarda her alanda 


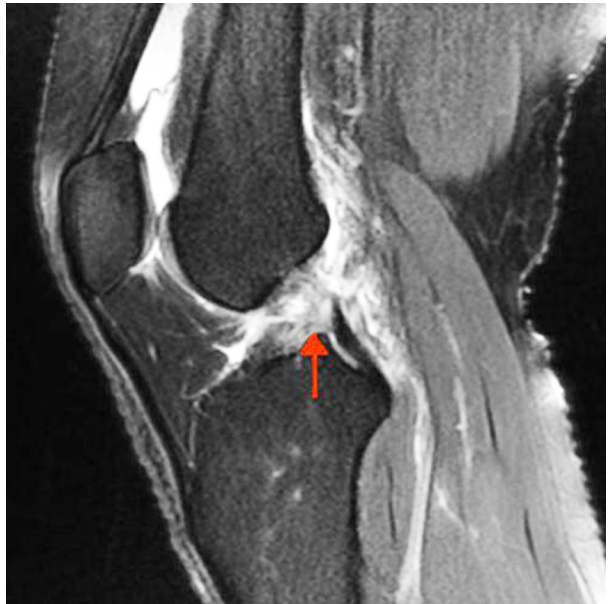

Şekil 11. $T 2$ ağılıklı sagittal $M R$ görüntüsü. ÖÇB'nin olması gereken bölgede ödem ve düzensiz ÖÇB lifleri (kırmızı ok) gözlenmekte.

kullanılmaya başlanan yapay zekanın ÖÇB yırtıklarının tespitinde kullanılmasını konu alan çalışmada Liu ve ark., ÖÇB yırtıklarının tespiti konusunda radyologların değerlendirmesi ile yapay zekâ arasında anlamlı bir fark bulamamışlardır. ${ }^{[25]}$

MR dizdeki diğer eşlik eden yaralanmaların ortaya konması açısından da önemlidir. ÖÇB yaralanmaları ile sıkça birlikte görülen menisküs yırtıkları, dış yan bağ, posterolateral köşe ve ALL hasarların tespiti ÖÇB ameliyatlarının planlamasında önemlidir. Kosy ve ark., bunlardan ALL hasarlarını inceledikleri çalışmada, ÖÇB yaralanması olan hastaların çekilen MR görüntülerinde \%10,7 oranında ALL hasarının tespit edilebileceğini bulmuşlardır. Ancak bu oranın altı haftadan sonra azaldığını, bunun nedeninin de ALL hasarının kısmen iyileşmesine ya da MR'de görünemez karakter almasına bağlı olabileceğini iddia etmişlerdir. ${ }^{[26]}$

\section{Tanı}

ÖÇB yaralanmalarının erken dönemde \%14,4 oranında teşhis edilebildiği bildirilmiştir. ${ }^{[27]}$ Yukarıda sözü edilen ve çok yaygın kullanılan belirtilerin (yaralanma esnasında "pop" sesi, dizde kayma, effüzyon, ağrı, oyuna devam edememek) ve testlerin (öne çekmece, Lachman ve pivot şift, lever belirtisi testi) ÖÇB yaralanmalarının tespitinde yeri olsa da hiç birisi tek başına tanı koydurucu değildir. ${ }^{[19,28,29]}$ Ancak birden çok testin ya da bulgunun pozitif olması teşhis ihtimalini yükseltmektedir. ${ }^{[29]}$ Benjaminse ve ark., yaptıkları çalışmada ÖÇB yırtıklarını teşhis etmek için en geçerli testin hem akut hem de kronik yırtıklarda çok spesifik olduğu için Lachman testi olduğunu bildirmişler. ${ }^{[30]}$ Lachman testi ÖÇB yırtıklarını tespit etmede her ne kadar çok özgül
(\%98) ise de duyarlılığı düşüktür (\%24). Yazarlar bu yüzden ikinci olarak da pivot şift testini önermişlerdir. ${ }^{[30]}$ Bunların dışında görüntüleme yöntemlerinden MR altın standart olarak kabul edilir. Ancak, özellikle kısmi yırtıklarda son kararı vermek için artroskopik muayene belirleyici olabilmektedir.

\section{KAYNAKLAR}

1. Gornitzky AL, Lott A, Yelli JL, Yellin JL, Fabricant PD, Lawrence JT, Ganley TJ. Sport-specific yearly risk and incidence of anterior cruciate ligament tears in high school athletes: A systematic review and meta-analysis. Am J Sports Med 2016;44(10):2716-23. Crossref

2. Irarrazaval S, Albers M, Chao T, Fu FH. Gross, arthroscopic and radiographic anatomies of the anterior cruciate ligament. Clin Sports Med 2017;36(1):9-23. Crossref

3. Mochizuki T, Nimura A, Yasuda K, Muneta T, Akta K. Anatomic and histological analysis of the midsubstance and fanlike extension fibers of the ACL. In: Siebold R, Dejour D, Zaffagnini S, editors. Anterior cruciate ligament reconstruction. A practical surgical guide. Luxemburg: ESSKA ASBL; 2014. pp.11-8.

4. Smigielski $R$, Zdanowicz $U$, Drwiega $M$, Ciszek B, Williams A. The anatomy of the anterior cruciate ligament and its relevance to the technique of reconstruction. Bone Joint J 2016;98-B(8):1020-6. Crossref

5. Sakane M, Fox RJ, Woo SL, Livesay GA, Li G, Fu FH. In situ forces in the anterior cruciate ligament and its bundles in response to anterior tibial loads. J Orthop Res 1997;15(2):285-93. Crossref

6. Boden BP, Dean GS, Feagin JA Jr, Garrett WE Jr. Mechanism of anterior cruciate ligament injury. Orthopaedics 2000;23(6):573-8. Crossref

7. Myer GD, Sugimoto D, Thomas S, Hewett TE. The influence of age on the $M$ effectiveness of neuromuscular training to reduce anterior cruciate ligament injury in female athletes: A meta-analysis. Am J Sports Med 2013;41(1):203-15. Crossref

8. Petersen W, Zantop T. Partial rupture of the anterior cruciate ligament. Arthroscopy 2006;22(11):1143-5. Crossref

9. Wagemakers HP, Luijsterburg PA, Boks SS, Heintjies EM, Berger MY, Verhaar JA, Koes BW, Bierma-Zeinstra SM. Diagnostic accuracy of history taking and physical examination for assessing anterior cruciate ligament lesions of the knee in primary care. Arch Phys Med Rehabil 2010;91(9):1452-9. Crossref

10. Fayard JM, Sonnery-Cottet B, Vrgoc G, O'Loghlin P, Dubois de Mont Marin G, Freychet B, Vieira TD, Thaunat M. Incidence and risk factors for a partial anterior cruciate ligament tear progressing to a complete tear after nonoperative treatment in patients younger than 30 years. Orthop J Sports Med 2019;7(7):232596711985662. Crossref

11. Song G, Zhang H, Wu G, Zhang J, Liu X, Xue Z, Qian Y, Feng $H$. Patients with high-grade pivot-shift phenomenon are associated with higher prevalence of anterolateral ligament injury after acute anterior cruciate ligament injuries. Knee Surg Sports Traumatol Arthrosc 2017;25(4):1111-6. Crossref

12. Puzzitiello RN, Agarwalla A, Zuke WA, Garcia GH, Forsythe $B$. Imaging diagnosis of injury to the anterolateral ligament in patients with anterior cruciate ligaments: Association of anterolateral ligament injury with other types of knee pathology and grade of pivot-shift examination: A systematic review. Arthroscopy 2018;34(9):2728-38. Crossref 
13. Hole RL, Lintner DM, Kamaric E, Moseley JB. Increased tibial translation after partial sectioning of the anterior cruciate ligament. Am J Sports Med 1996;24(4):556-60. Crossref

14. Vaudreuil NJ, Rothrauff BB, de SA D, Musahl V. The pivot shift: Current experimental methodology and clinical utility for anterior cruciate rupture and associated injury. Curr Rev Musculoskelet Med 2019;12(1):41-9. Crossref

15. Nishida $K$, Matsushita $T$, Hoshino $Y$, Araki D, Matsumoto $T$, Niikura T, Kuroda R. The influences of chronicity and meniscal injuries on pivot shift in anterior cruciate ligament-deficient knees: Quantitative evaluation using an electromagnetic measurement system. Arthroscopy 2020. Crossref

16. Kittl C, El-Daou H, Athwal KK, Gupte CM, Weiler A, Williams A, Amis AA. The role of the anterolateral structures and the $A C L$ in controlling laxity of the intact and $A C L$-deficient knee. Am J Sports Med 2016;44(2)345-54. Crossref

17. Noyes FR, Huser LE, Levy MS. Rotational knee instability in ACL-deficient knees. J Bone Joint Surg Am 2017;99(4):30514. Crossref

18. Song G, Zhang H, Wang Q, Zhang J, Li Y, Feng H. Risk factors associated with grade 3 pivot shift after acute anterior cruciate ligament injuries. Am J Sports Med 2016;44(2):3629. Crossref

19. Lelli A, Di Turi RP, Spenciner DB, Domini M. The "lever sign": a new clinical test for diagnosis of anterior cruciate ligament rupture. Knee Surg Sports Traumatol Arthrosc 2016;24(9):2794-7. Crossref

20. Siebold R, Fu FH. Assessment and augmentation of symptomatic anteromedial or posterolateral bundle tears of the anterior cruciate ligament. Arthroscopy 2008;24(11):1289-98. Crossref

21. Ryu SM, Na HD, Shon OJ. Diagnostic Tools for acute anterior cruciate ligament injury: GNRB, Lachman Test, Telos. Knee Surg Relat Res 2018;30(2):121-7. Crossref

22. Kosaka M, Naklase J, Toratani T, Ohashi Y, Kitaoka K, Yamada H, Komura K, Nakamura S, Tsuchiya H. Oblique coronal and oblique sagittal MRI for diagnosis of anterior cruciate ligament tears and evaluation of anterior cruciate ligament remnant tissue. Knee 2014;21(1):54-7. Crossref
23. Lee JK, Yao L, Phelps CT, Wirth CR, Czajka J, Lozman J. Anterior cruciate ligament tears: MR imaging compared with arthroscopy and clinical tests. Radiology 1988;166(3):8614. Crossref

24. Vahey TN, Broome DR, Kayes KJ, Shelburn KD. Acute and chronic tears of the anterior cruciate ligament: differential features at MR imaging. Radiology 199;181(1):251-3. Crossref

25. Liu F, Guam B, Zhou Z, Samsonov A, Rosas H, Lian K, Sharma R, Kanarek A, Kim J, Guermazi A, Kijowski R. Fully automated diagnosis of anterior cruciate ligament tears on knee MR imaging by using deep learning. RSNA Radiology: Artificial Intelligence 2019;1(3):180091. Crossref

26. Kosy JD, Schranz PJ, Patel A, Anaspure R, Mandalia V. The magnetic resonance imaging appearance of the anterolateral ligament of the knee in association with anterior cruciate rupture. Skeletal Radiol 2017;46(9):1193-200. Crossref

27. Parwaiz H, Teo AQA, Servant C. Anterior cruciate ligament injury: A persistently difficult diagnosis. Knee 2016;23(1):116-20. Crossref

28. Leblanc MC, Kowalczuk M, Andruszkiewicz N, Simunovic N, Farrokhyar F, Turnbull TL, Debski RE, Ayeni OR. Diagnostic accuracy of physical examination for anterior knee instability: a systemic review. Knee Surg Sports Traumatol 2015;23(10):2805-13. Crossref

29. Swain MS, Henschke N, Kamper SJ, Downie AS, Koes BW, Maher CG. Accuracy of clinical tests in the diagnosis of anterior cruciate ligament injury: A systematic review. Chiropr Man Therap 2014;22:25. http://www.chiromt.com/ content/22/1/25

30. Benjaminse A, Gokeler A, van der Schans CP. Clinical diagnosis of an anterior cruciate ligament rupture: A metaanalysis. J Orthop Sports Phys Ther 2006;36(5):267-86. Crossref 